Vol. 8 (4): 761-766 (2018)

\title{
RISK FACTORS ASSOCIATED WITH CAROTID ARTERY DISEASE IN PATIENTS UNDERGOING CORONARY ARTERY BYPASS SURGERY
}

\author{
Petrika Gjergo $^{1 *}$, Aferdita Veseli ${ }^{1}$, Hortensia Gjergo ${ }^{2}$, Artan Simaku $^{3}$, Edmond Kapedani $^{4}$ \\ ${ }^{1 *}$ Clinic of Cardiovascular Surgery, UHC "Mother Theresa" Tirana, Albania; \\ ${ }^{2}$ Clinic of Cardiology, UHC "Mother Theresa" Tirana, Albania; \\ ${ }^{3}$ Public Health Institute, Tirana, Albania; \\ ${ }^{4}$ Faculty of Medicine, Catholic University "Our Lady of Good Counsel” Tirana, Albania; \\ *Corresponding author: Petrika Gjergo, email: tensi1975@yahoo.com;
}

Received May, 2018; Accepted June, 2018; Published July, 2018;

DOI: https://doi.org/10.31407/ijees8416

UOI license: http://u-o-i.org/1.01/ijees/46950646

\begin{abstract}
Stroke and other ischemic neurological events are among the most dreaded adverse events following cardiac surgery. The stroke risk in patients undergoing coronary artery bypass graft surgery (CABG) is estimated at $2 \%$. We performed a retrospective analysis of patients with and without severe carotid artery disease who were scheduled for CABG to determine what variables were associated with severe carotid artery stenosis. This is a case control study. 49 patients with carotid stenosis $\geq 70 \%$ identified by duplex ultrasound and coronary artery disease (CAD) scheduled for CABG at the University Hospital Centre "Mother Theresa" were matched by age and gender with 49 patients with carotid stenosis $<50 \%$. In univariate analysis, a statistically significant difference was found between cases and controls regarding the CAD extent $(\mathrm{p}=0.03)$, hypertriglyceridemia $(\mathrm{p}<0.001)$ and carotid bruit $(\mathrm{p}<0.001)$. In multivariate analysis by logistic regression, independent risk factors associated with stenosis were smoking $(\mathrm{p}=0.03)$ and carotid bruit $(\mathrm{p}<0.001)$. All patients with CAS should have medical management that includes control of hypertension, cholesterol levels, and diabetes, administration of antiplatelet agents, and smoking cessation.
\end{abstract}

Keywords: carotid arteries, atherosclerosis, coronary artery disease, coronary artery, bypass grafting. 